\title{
Interactions of meteoric smoke particles with sulphuric acid in the Earth's stratosphere
}

\author{
R. W. Saunders ${ }^{1}$, S. Dhomse ${ }^{2}$, W. S. Tian ${ }^{3}$, M. P. Chipperfield ${ }^{2}$, and J. M. C. Plane ${ }^{1}$ \\ ${ }^{1}$ School of Chemistry, University of Leeds, Leeds LS2 9JT, UK \\ ${ }^{2}$ School of Earth and Environment, University of Leeds, Leeds LS2 9JT, UK \\ ${ }^{3}$ College of Atmospheric Sciences, Lanzhou University, Lanzhou 730000, China \\ Correspondence to: J. M. C. Plane (j.m.c.plane@leeds.ac.uk) \\ Received: 23 December 2011 - Published in Atmos. Chem. Phys. Discuss.: 17 January 2012 \\ Revised: 10 April 2012 - Accepted: 3 May 2012 - Published: 16 May 2012
}

\begin{abstract}
Nano-sized meteoric smoke particles (MSPs) with iron-magnesium silicate compositions, formed in the upper mesosphere as a result of meteoric ablation, may remove sulphuric acid from the gas-phase above $40 \mathrm{~km}$ and may also affect the composition and behaviour of supercooled $\mathrm{H}_{2} \mathrm{SO}_{4}$ $\mathrm{H}_{2} \mathrm{O}$ droplets in the global stratospheric aerosol (Junge) layer.

This study describes a time-resolved spectroscopic analysis of the evolution of the ferric $\left(\mathrm{Fe}^{3+}\right)$ ion originating from amorphous ferrous $\left(\mathrm{Fe}^{2+}\right)$-based silicate powders dissolved in varying $\mathrm{Wt} \%$ sulphuric acid (30-75\%) solutions over a temperature range of 223-295 K. Complete dissolution of the particles was observed under all conditions. The first-order rate coefficient for dissolution decreases at higher $\mathrm{Wt} \%$ and lower temperature, which is consistent with the increased solution viscosity limiting diffusion of $\mathrm{H}_{2} \mathrm{SO}_{4}$ to the particle surfaces. Dissolution under stratospheric conditions should take less than a week, and is much faster than the dissolution of crystalline $\mathrm{Fe}^{2+}$ compounds.

The chemistry climate model UMSLIMCAT (based on the UKMO Unified Model) was then used to study the transport of MSPs through the middle atmosphere. A series of model experiments were performed with different uptake coefficients. Setting the concentration of $1.5 \mathrm{~nm}$ radius MSPs at $80 \mathrm{~km}$ to $3000 \mathrm{~cm}^{-3}$ (based on rocket-borne charged particle measurements), the model matches the reported $\mathrm{Wt} \%$ Fe values of $0.5-1.0$ in Junge layer sulphate particles, and the MSP optical extinction between 40 and $75 \mathrm{~km}$ measured by a satellite-borne spectrometer, if the global meteoric input rate is about 20 tonnes per day. The model indicates that an uptake coefficient $\geq 0.01$ is required to account for the ob-
\end{abstract}

served two orders of magnitude depletion of $\mathrm{H}_{2} \mathrm{SO}_{4}$ vapour above $40 \mathrm{~km}$.

\section{Introduction}

The acidic weathering of ferrous $\left(\mathrm{Fe}^{2+}\right)$-based silicate minerals such as olivines $\left(\mathrm{Mg}_{2 x} \mathrm{Fe}_{2-2 x} \mathrm{SiO}_{4}\right)$ and pyroxenes $\left(\mathrm{Mg}_{\mathrm{x}} \mathrm{Fe}_{1-\mathrm{x}} \mathrm{SiO}_{3}\right)$, where $0 \leq x \leq 1$, is an important pathway to the formation of secondary minerals on Earth (Loughnan, 1969; White, 1995). The weathering process is complex and involves dissolution and oxidation steps, but studies indicate that the Fe-rich olivine/pyroxene structures are more soluble at low temperatures and weather faster than Fe-poor or non-Fe minerals (Siever and Woodford, 1979). Similar processes also occur on Mars, but under very different chemical conditions (Burns, 1993; Hurowitz et al., 2006), and are also likely to lead to stabilised hydrated and sulphate-complexed ferric $\left(\mathrm{Fe}^{3+}\right)$ ion species in the Martian permafrost (Burns, 1987). Amorphous silicate structures are the leading candidates for meteoric smoke particles or MSPs (Hervig et al., 2009; Saunders and Plane, 2011). These are nanoparticles formed by the recondensation of primarily $\mathrm{Fe}, \mathrm{Mg}$ and $\mathrm{Si}$ oxide species resulting from the ablation of meteoroids passing through planetary upper atmospheres (Plane, 2003).

Charged MSPs have been detected in the Earth's upper atmosphere by rocket-borne and radar techniques (see, e.g. (Rapp et al., 2007)) which indicate typical total (neutral + charged) particle numbers of a few thousand per $\mathrm{cm}^{-3}$ above $75 \mathrm{~km}$. More recently, the first optical detection (at $1.037 \mu \mathrm{m}$ ) of MSPs between $\sim 40$ and $80 \mathrm{~km}$ by 
satellite-borne spectrometry was used to infer the possible particle composition (Hervig et al., 2009). Satellite data has also been modelled to investigate the likely extent of optical extinction by MSPs between 30 and $40 \mathrm{~km}$ (Neely et al., 2011).

MSPs are thought to participate in the nucleation of waterice clouds in the mesosphere (Rapp and Thomas, 2006; Gumbel and Megner, 2009), and also impact on trace vapours such as $\mathrm{H}_{2} \mathrm{SO}_{4}$ and $\mathrm{HNO}_{3}$ throughout the middle atmosphere (Turco et al., 1981; Prather and Rodriguez, 1988; Mills et al., 2005). After MSPs have been transported down from the mesosphere in the winter polar vortex (Curtius et al., 2005), they are thought to be assimilated in liquid (supercooled) $\mathrm{H}_{2} \mathrm{SO}_{4}-\mathrm{H}_{2} \mathrm{O}$ droplets (typically $40-75 \mathrm{Wt} \%$ acid composition, radius $>100 \mathrm{~nm}$ ) in the stratospheric aerosol or Junge layer which is located between 15 and $30 \mathrm{~km}$ in altitude (Carslaw et al., 1997; Deshler, 2008). These droplets can act as nuclei for polar stratospheric cloud (PSC) formation via uptake of water and nitric acid at temperatures below $\sim 210 \mathrm{~K}$ (Voigt et al., 2005).

Iron and magnesium of meteoric origin have been identified in positive ion spectra from droplets sampled in situ in the lower stratosphere (Murphy et al., 1998; Cziczo et al., 2001), with approximately half of the analysed particles reported to contain $0.5-1.0 \mathrm{Wt} \%$ of meteoric iron. Typical spectra of the sampled particles were closely replicated by the dissolution of $\mathrm{Fe}$ and $\mathrm{Mg}$ compounds in a $65 \%$ (Wt) $\mathrm{H}_{2} \mathrm{SO}_{4}$ solution. At the low temperatures present in the stratosphere (180-240 K), the question of particle solubility is key in beginning to understand the composition of stratospheric aerosol, as the relative proportions of solid/solution phase metals in such aerosol are likely to control the freezing behaviour of the $\mathrm{H}_{2} \mathrm{SO}_{4}-\mathrm{H}_{2} \mathrm{O}$ droplets (Wise et al., 2003). Previous studies (e.g. Biermann et al., 1996) have concluded that meteoric material would not be an efficient seed for heterogeneous droplet freezing, but the chosen material used was not characteristic of the particle composition identified in stratospheric aerosol (Cziczo et al., 2001).

Balloon-borne mass spectroscopic measurements made in the 1980s e.g. (Arnold et al., 1981; Viggiano and Arnold, 1981; Schlager and Arnold, 1987) delineate three distinct regions in the stratosphere where the concentration of gasphase sulphuric acid varies significantly. Comparatively low concentrations, typically ranging between $10^{4}$ and $10^{5} \mathrm{~cm}^{-3}$ (outside of periods of major volcanic activity) are found below $30 \mathrm{~km}$, where temperatures below $230 \mathrm{~K}$ result in the condensation of binary solutions of $\mathrm{H}_{2} \mathrm{SO}_{4}-\mathrm{H}_{2} \mathrm{O}$ to form stratospheric sulphate aerosol (SSA). Between 30 and $35 \mathrm{~km}$, with increasing temperatures, the gas-phase concentration increases to $10^{6}-10^{7} \mathrm{~cm}^{-3}$. Above $35 \mathrm{~km}$, measurements indicate a 'turning-point', whereby concentrations begin to decrease up to $\sim 40 \mathrm{~km}$. Above this altitude, data is restricted to a couple of balloon flights (Arijs et al., 1983, 1985), with $\mathrm{H}_{2} \mathrm{SO}_{4}$ levels at $45 \mathrm{~km}$ falling to $\sim 10^{4}-10^{5} \mathrm{~cm}^{-3}$.
The reasons for an approximate two orders of magnitude depletion at $45 \mathrm{~km}$ (compared with the peak at $\sim 35 \mathrm{~km}$ ) has long been the subject of debate, with gas-phase chemistry, photolysis and heterogeneous uptake on MSPs/metal atoms being proposed as possible removal processes (Turco et al., 1981; Vaida et al., 2003). A 1-D modelling study of MSP acid interaction (Turco et al., 1981), where chemical neutralisation (resulting from metal atom-acid molecule collisions) was assumed, indicated that a downward metal atom flux of $5 \times 10^{6} \mathrm{~cm}^{-2} \mathrm{~s}^{-1}$ from the upper mesosphere (equivalent to a global meteoric mass influx of $\sim 200$ tonnes per day) was required to account for the observed depletion in $\mathrm{H}_{2} \mathrm{SO}_{4}$ at $45 \mathrm{~km}$. However, this flux value lies significantly beyond the upper limit of what is now currently considered to be a likely range of between $\sim 5$ and $50 \mathrm{t} \mathrm{d}^{-1}$ (tonnes per day) (Vondrak et al., 2008). In addition, this model involved an arbitrary choice of collision rate scaling with which to determine the acid loss to smoke particles (Turco et al., 1981). A more recent 2-D modelling study of $\mathrm{H}_{2} \mathrm{SO}_{4}$ photolysis and sulphur gas and aerosol chemistry concluded that visible wavelength photolysis $\left(\mathrm{H}_{2} \mathrm{SO}_{4}+h v \rightarrow \mathrm{SO}_{3}+\mathrm{H}_{2} \mathrm{O}\right)$ via $\mathrm{OH}$ stretch excitation could not account for the loss of $\mathrm{H}_{2} \mathrm{SO}_{4}$ vapour above $40 \mathrm{~km}$. With VUV photolysis of $\mathrm{H}_{2} \mathrm{SO}_{4}$ being too slow below $80 \mathrm{~km}$, it was therefore suggested that irreversible loss to smoke particles, although not treated in their study, was the most likely cause of the observed gas-phase depletion above $40 \mathrm{~km}$ (Mills et al., 2005).

This paper describes a combined laboratory and modelling study. The laboratory component measured the rates at which MSP analogue particles dissolve in concentrated $\mathrm{H}_{2} \mathrm{SO}_{4} / \mathrm{H}_{2} \mathrm{O}$ solutions under stratospheric conditions. The modelling component explored the distribution of MSPs in the middle atmosphere, constrained by the available observations: rocket-borne particle detectors above $80 \mathrm{~km}$ (Gelinas et al., 2005; Lynch et al., 2005), optical extinction between 40 and $80 \mathrm{~km}$ (Hervig et al., 2009), and the Fe Wt \% in Jungle layer droplets (Murphy et al., 1998; Cziczo et al., 2001). From this it was possible to constrain the uptake coefficient of $\mathrm{H}_{2} \mathrm{SO}_{4}$ on MSPs required to explain the observed decrease in concentration of this acid vapour above $40 \mathrm{~km}$.

\section{Acid dissolution of amorphous MSP analogues}

\subsection{Experimental technique}

We conducted a series of experiments in which a sol-gel synthesised amorphous fayalite $\left(\mathrm{Fe}_{2} \mathrm{SiO}_{4}\right)$ powder was dissolved in $30-75 \mathrm{Wt} \%$ acid solutions over a temperature range of $223-295 \mathrm{~K}$. This composition was taken as a representative analogue for MSPs (Saunders and Plane, 2006). Other mixed metal $(x>0)$ olivine and pyroxene compositions are also likely in MSPs. We therefore also synthesised $\mathrm{MgFeSiO}_{4}, \mathrm{FeSiO}_{3}$ and $\mathrm{MgFeSiO}_{3}$ powders using the solgel process and studied their dissolution characteristics over 


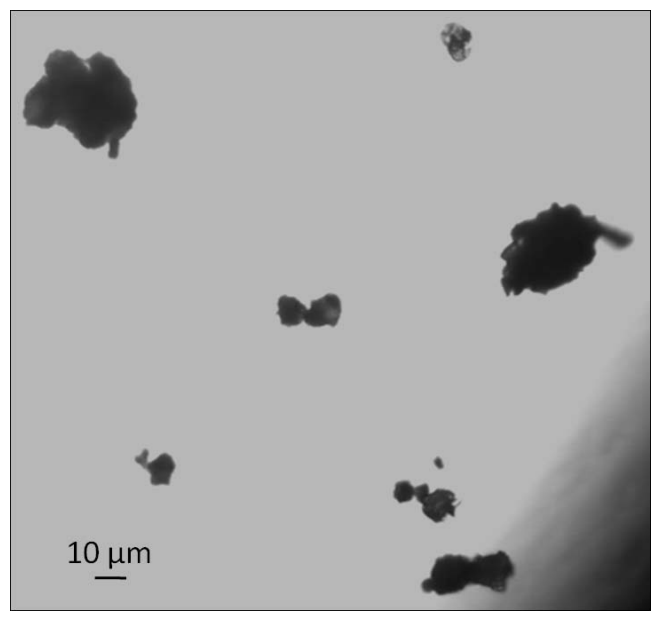

Fig. 1. Optical microscope image of synthesised silicate particles used in the acid solution-powder experiments.

more limited temperature/acid $\mathrm{Wt} \%$ ranges for comparison with the fayalite powder. Particle dissolution and the Fe oxidation state were monitored spectroscopically to determine the rate and extent of particle solubility. The data was used to determine reaction rate coefficients for specific temperature/acid $\mathrm{Wt} \%$ combinations, and then activation energies for the silicate powder dissolution process.

Amorphous powders of the iron $(x=0)$ end-members of the olivine (fayalite) and pyroxene (ferrosilite) series, and mixed composition powders $(x \sim 0.5)$ were synthesised in accordance with procedures described by (Thompson et al., 1996). Briefly, solutions of either sodium metasilicate $\left(\mathrm{Na}_{2} \mathrm{SiO}_{3}\right)$ or orthosilicate $\left(\mathrm{Na}_{4} \mathrm{SiO}_{4}\right)$ were mixed in the desired stoichiometric amounts with $0.1 \mathrm{M}$ solutions of $\mathrm{Fe}\left[\mathrm{NH}_{4}\right]_{2}\left(\mathrm{SO}_{4}\right)_{2} \cdot 6 \mathrm{H}_{2} \mathrm{O}$ (Mohr's salt), or both Mohr's salt and $\mathrm{MgCl}_{2}$ for the generation of mixed composition powders. In each case, the gelatinous precipitate immediately formed was left for 1-2 days, before excess liquid was decanted and the solids washed thoroughly to remove any byproducts. The remaining liquid was evaporated using a heating plate, and the solids powdered using a pestle and mortar. The resulting powders were then stored in a dessicator, prior to IR characterisation and then sulphuric acid dissolution studies.

Figure 1 shows a microscope image of the synthesised Fesilicate particles, which exhibit a range of shapes and of sizes from $\sim 1-50 \mu \mathrm{m}$ (the applicability of particles in this size range to MSPs is discussed below). Mid-IR spectra (4000$450 \mathrm{~cm}^{-1}$ ) were taken directly from the solid samples using an FT-IR spectrometer (Spectrum One, PerkinElmer) at a resolution of $1 \mathrm{~cm}^{-1}$. All powders showed a broad, structureless peak between 800 and $1000 \mathrm{~cm}^{-1}$, corresponding to the Si-O stretch observed in amorphous silicates (Draine, 2003). For subsequent analysis of reactions of synthesised silicate powders with sulphuric acid, weighed amounts (typically 5-
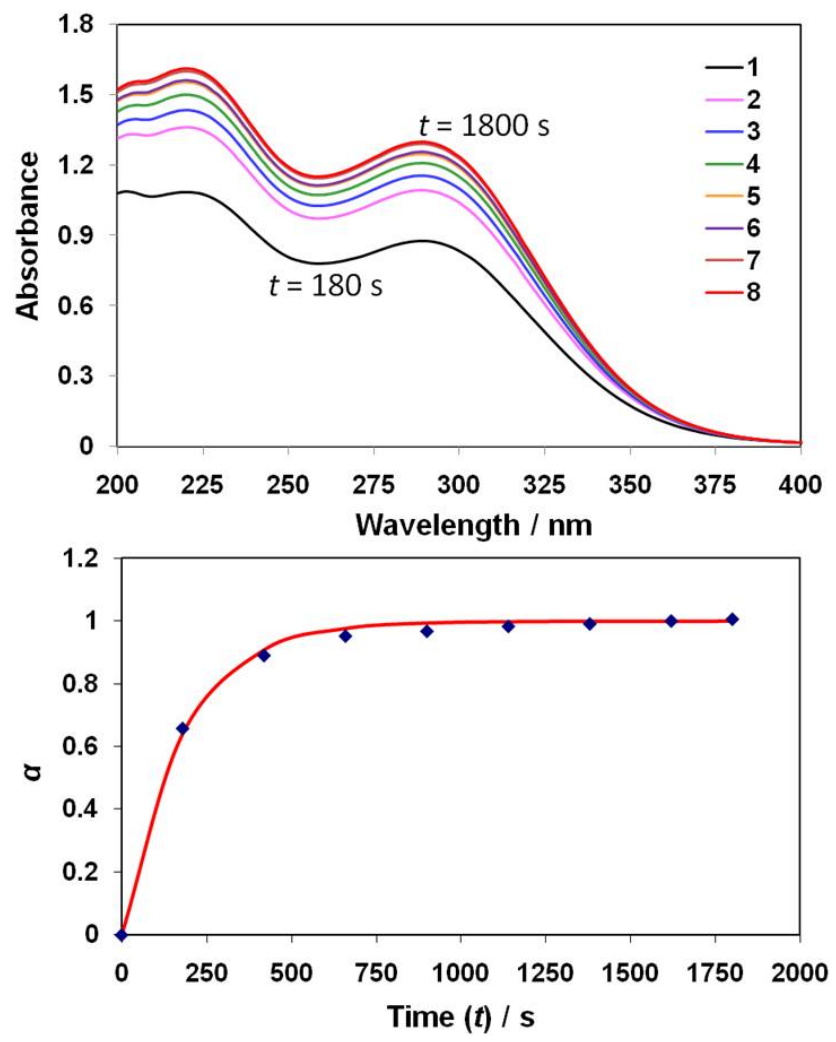

Fig. 2. The top panel shows a time series of UV-visible spectra taken from a $75 \% \mathrm{Wt} \mathrm{H}_{2} \mathrm{SO}_{4}$ solution at $273 \mathrm{~K}$, to which amorphous fayalite powder had been added. The time at which each numbered (consecutive) spectrum was taken is indicated in the bottom panel, which is a plot of the ratio $(\alpha)$ of measured absorbance at the $289 \mathrm{~nm}$ $\left(\mathrm{Fe}\left[\mathrm{SO}_{4}\right]_{2}^{-}\right)$peak to the maximum (final) absorbance at time (t).

$10 \mathrm{mg}$ ) of the $\mathrm{Fe}$ and $\mathrm{Fe}-\mathrm{Mg}$ silicate powders were placed in stoppered conical flasks with a total volume of $50 \mathrm{ml}$ of a $\mathrm{H}_{2} \mathrm{SO}_{4}$ solution (98\%), diluted to a desired acid $\mathrm{Wt} \%$ in deionised water. Solution spectra from $200-600 \mathrm{~nm}$ at a resolution of $1 \mathrm{~nm}$ were taken using a UV-visible spectrometer (Perkin Elmer-Lambda 900) with $1 \mathrm{~cm}$ quartz cuvettes, at regular time intervals. For experiments below room temperature, an immersion cooler (Neslab CC100) was used in combination with a methanol bath, in which the acid solution was equilibrated prior to addition of the sample powder and periodic extraction of aliquots for spectroscopic analysis. Due to the increasing solution viscosity at lower temperature and higher acid $\mathrm{Wt} \%$, it was necessary to allow solutions of $>50 \mathrm{Wt} \%$ at $T<273 \mathrm{~K}$ to stand for a $5-10 \mathrm{~min}$ period after removal from the bath, before spectra acquisition was possible.

\subsection{Experimental results}

Figure 2 shows a representative data set for the fayaliteacid solution experiments. The top panel shows the evolution with time of the UV-visible absorbance for $\lambda \leq 400 \mathrm{~nm}$ 
(no absorbance was observed at longer wavelengths) for a $75 \% \mathrm{Wt}$ acid solution at $273 \mathrm{~K}$, with $8.1 \mathrm{mg}$ of the $\mathrm{Fe}_{2} \mathrm{SiO}_{4}$ powder added to give $\left[\mathrm{Fe}^{2+}\right]_{t=0} \sim 7.9 \times 10^{-4} \mathrm{M}$ in $50 \mathrm{ml}$ of the acid solution. The data shows the increase in absorbance for peaks at $289 \mathrm{~nm}$ and $220 \mathrm{~nm}$ from the first spectrum taken 3 minutes after addition of the powder, to the final spectrum after 30 minutes, at which point no further increase in absorbance was observed.

The aqueous solution spectroscopy of $\mathrm{Fe}^{2+} / \mathrm{Fe}^{3+}$ ions has been extensively studied. Whilst the $\mathrm{Fe}^{2+}$ ion exhibits only a small continuous absorbance (molar extinction $\varepsilon<50 \mathrm{~L} \mathrm{~mol}^{-1} \mathrm{~cm}^{-1}$ ) for $\lambda<300 \mathrm{~nm}$ (Potterill, 1936), the "bare" $\mathrm{Fe}^{3+}$ ion displays much greater $\varepsilon$ values in this region (increasing to $>3000 \mathrm{~L} \mathrm{~mol}^{-1} \mathrm{~cm}^{-1}$ for $\lambda<250 \mathrm{~nm}$ (Whiteker and Davidson, 1953)). However, in acidic solutions, hydration of the ion (in weak solutions) leads to the formation of the $\mathrm{Fe}(\mathrm{OH})^{2+}$ species (absorbance peak at $\sim 300 \mathrm{~nm}$ with $\varepsilon \sim 2500 \mathrm{~L} \mathrm{~mol}^{-1} \mathrm{~cm}^{-1}$ ), whilst complexation with sulphate ions in strongly acidic solutions produces $\mathrm{Fe}\left(\mathrm{SO}_{4}\right)^{+}$(peak at $\sim 302 \mathrm{~nm}, \varepsilon \sim 2200 \mathrm{~L} \mathrm{~mol}^{-1} \mathrm{~cm}^{-1}$ ), and $\mathrm{Fe}\left(\mathrm{SO}_{4}\right)_{2}^{-}$species, whose peak absorbance shifts to $\sim 290 \mathrm{~nm}$ ( $\varepsilon \sim 3000 \mathrm{~L} \mathrm{~mol}^{-1} \mathrm{~cm}^{-1}$ ) at increasing acid solution strength (Wt \%) (Whiteker and Davidson, 1953).

The spectra observed in Fig. 2 are therefore consistent with increasing absorption by the bare $\mathrm{Fe}^{3+}$ ion at $220 \mathrm{~nm}$, and the $\mathrm{Fe}\left(\mathrm{SO}_{4}\right)_{2}^{-}$complex ion at $289 \mathrm{~nm}$. To determine the total final $\left[\mathrm{Fe}^{3+}\right]$ in solution, an $\varepsilon$ value of $4565 \mathrm{~L} \mathrm{~mol}^{-1} \mathrm{~cm}^{-1}$ at $220 \mathrm{~nm}$ was used (Scharf and Lee, 1962). The final absorbance value of 1.3 at $289 \mathrm{~nm}$ indicates a $\left[\mathrm{Fe}^{3+}\right]_{\text {complexed }}$ of $4.3 \times 10^{-4} \mathrm{M}(=1.3 / 3000)$ or $\sim 55 \%$ of $\left[\mathrm{Fe}^{2+}\right]_{t=0}$, whilst $A_{\max }=1.61$ at $220 \mathrm{~nm}$ is consistent with a $\left[\mathrm{Fe}^{3+}\right]_{\text {bare }}=3.5 \times 10^{-4} \mathrm{M}(=1.61 / 4565)$ or $\sim 44 \%$ of $\left[\mathrm{Fe}^{2+}\right]_{t=0}$ to give a total $\left[\mathrm{Fe}^{3+}\right]$ of $7.8 \times 10^{-4} \mathrm{M}$. This indicates that, to within experimental error, complete conversion of solid-phase ferrous ion through to the ferric ion in solution occurred.

The bottom panel of Fig. 2 shows the calculated values (solid triangles) of the ratio $(\alpha)$ of measured absorbance at time $(t)$ to the final (maximum) value. In addition, the red line is a least squares optimised fit to the data points using an expression of the form;

$\alpha=1-\exp (-k t)$

where $k\left(\mathrm{~s}^{-1}\right)$ is a single first-order rate coefficient which encompasses all reaction processes. These include: (i) $\mathrm{H}_{2} \mathrm{SO}_{4}$ diffusion to particle surfaces; (ii) oxidation of $\mathrm{Fe}^{2+}$ to $\mathrm{Fe}^{3+}$; (iii) dissolution; and (iv) ion hydration/complexation in solution. For the $75 \% \mathrm{Wt}-273 \mathrm{~K}$ solution, $k$ was determined to be $(5.6 \pm 0.3) \times 10^{-3} \mathrm{~s}^{-1}$.

Similar spectral data was acquired for $75 \% \mathrm{Wt}$ acidfayalite powder solutions at $T=223 \mathrm{~K}, 243 \mathrm{~K}, 263 \mathrm{~K}$ and $295 \mathrm{~K}$, and for $30 \%, 40 \%, 50 \%$ and $60 \% \mathrm{Wt}$ solutions at these same temperatures (except for the $30 \%$ solution at $223 \mathrm{~K}$, where solution freezing occurs), yielding $k$ for each
Table 1. Measured activation energies $\left(E_{\mathrm{a}}\right)$ and pre-exponential factors $(A)$ for the reaction rate coefficient for the dissolution of amorphous fayalite $\left(\mathrm{Fe}_{2} \mathrm{SiO}_{4}\right)$ powder in $\mathrm{H}_{2} \mathrm{SO}_{4} / \mathrm{H}_{2} \mathrm{O}$ solutions of varying $\mathrm{Wt} \%$.

\begin{tabular}{lll}
\hline Wt $\%$ acid solution & $E_{\mathrm{a}} / \mathrm{kJ} \mathrm{mol}^{-1}$ & $\ln A$ \\
\hline 30 & 27.6 & 7.079 \\
40 & 34.2 & 9.671 \\
50 & 42.1 & 12.985 \\
60 & 49.9 & 16.050 \\
75 & 59.9 & 21.200 \\
\hline
\end{tabular}

set of conditions. Experiments at temperatures below $223 \mathrm{~K}$ proved to be impractical due to the rapidly increasing viscosity of the solutions, as discussed below. In all cases (over different timescales), $100 \%$ conversion of initial $\mathrm{Fe}^{2+}$ in the added fayalite powder sample to $\mathrm{Fe}^{3+}$ in solution was recorded. The main differences observed in experiments with varying acid solution strengths (at the same temperature) were: (i) a shift in the complexed ion peak from $289 \mathrm{~nm}$ (75\% solution) to $\sim 300 \mathrm{~nm}(30 \%$ ); (ii) an increase in the ratio of the peak absorbance at $220 \mathrm{~nm}$ to the absorbance between $289-300 \mathrm{~nm}$, from 1.3 to 1.9 as the $\% \mathrm{Wt}$ decreased from 75 to $30 \%$, consistent with a final $\mathrm{Fe}^{3+}$ solution content of approximately equal amounts of bare and complexed ion; and (iii) a decrease in $k$ at higher acid Wt \%. Similarly, at constant acid $\mathrm{Wt} \%, k$ decreased at lower temperatures, the complexed $\mathrm{Fe}^{3+}$ peak shifted to lower wavelength, and the peak absorbance ratio decreased. Qualitatively, the decrease in rate coefficient with decreasing temperature and increasing acid $\mathrm{Wt} \%$ is consistent with increasing solution viscosity $\eta$ (and hence $\mathrm{H}_{2} \mathrm{SO}_{4}$ diffusion coefficient) for these conditions. For example, $\eta(75 \% \mathrm{Wt}) \sim 13 \mathrm{cP}$ compared with $\eta(30 \% \mathrm{Wt}) \sim 2 \mathrm{cP}$ at $295 \mathrm{~K}$; whilst at $223 \mathrm{~K}, \eta(75 \% \mathrm{Wt})$ $\sim 1450 \mathrm{cP}$ compared with $\eta(30 \% \mathrm{Wt}) \sim 50 \mathrm{cP}$ (Williams and Long, 1995). That is, the diffusion coefficient $(D \alpha T / \eta)$ of $\mathrm{H}_{2} \mathrm{SO}_{4}$ in a $75 \% \mathrm{Wt}$ solution at $223 \mathrm{~K}$ is $\sim 150$ times smaller than at $295 \mathrm{~K}$, and 29 times smaller than for a $30 \% \mathrm{Wt}$ solution at $223 \mathrm{~K}$. This compares with $k$ decreasing between 295 and $223 \mathrm{~K}$ by factors of $\sim 2700(75 \% \mathrm{Wt})$ and $\sim 27(30 \%)$. For temperatures colder than those accessed in our experiments $(T<223 \mathrm{~K})$, solution viscosity would rapidly increase e.g. $\eta(75 \% \mathrm{Wt}) \sim 3.5 \times 10^{5} \mathrm{cP}$ at $200 \mathrm{~K}$, which should result in a corresponding further decrease in $k$.

Casting the temperature dependence of $k$ at each Wt \% solution in Arrhenius form (i.e., $\ln k$ versus $1 / T$ ) yields the activation energy $\left(E_{a}\right)$ and pre-exponential factor $A$. These are listed in Table 1 and can be used to calculate $k$ (Wt \% $=30 \%-$ $75 \%, T=223-295 \mathrm{~K}$ ) and hence estimate the characteristic time for any fraction of the initial $\mathrm{Fe}^{2+}$ in the fayalite powder to be converted into $\mathrm{Fe}^{3+}$. Figure 3 is a contour plot showing the time taken in hours for $99.9 \%$ of particle $\mathrm{Fe}^{2+}$ to be dissolved to $\mathrm{Fe}^{3+}$, as a function of $\mathrm{Wt} \%$ and $T$. Under 


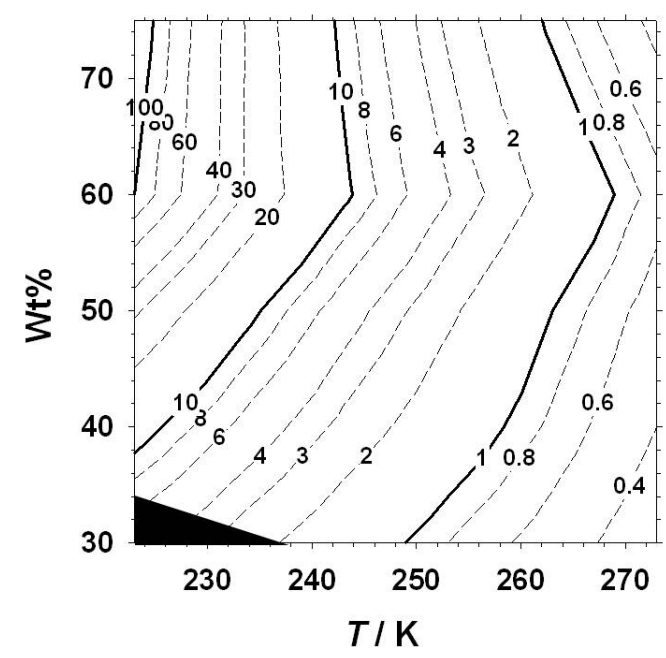

Fig. 3. Contour plots showing the calculated time in hours for the dissolution $(>99 \%)$ of $\mathrm{Fe}^{2+}$ ions from fayalite powder as a function of temperature $(223 \mathrm{~K}-273 \mathrm{~K})$ and $\mathrm{Wt} \%$ acid solution $(30 \%-$ $75 \%$ ). The black shaded area indicates the conditions under which hexagonal water-ice (Ih) formation occurs in $\mathrm{H}_{2} \mathrm{SO}_{4}-\mathrm{H}_{2} \mathrm{O}$ solutions.

the most "extreme" conditions ( $75 \%$ acid/223 K) amenable to spectroscopic analysis, the complete conversion of $\mathrm{Fe}^{2+}$ in particles to $\mathrm{Fe}^{3+}$ in solution takes $\sim 128$ h, i.e. 6 days. It should be stressed that these timescales are likely to represent upper limits for such a process involving 'real' MSPs in the upper atmosphere, which typically are much smaller (below $20 \mathrm{~nm}$ in radius) than those used in our experiments. The laboratory production of such small nanoparticle sizes is not currently possible either through direct synthesis or by further grinding of micron-sized particle powders. At these small dimensions, higher surface area-to-volume ratios are likely to lead to enhanced initial uptake of acid molecules and dissolution (Hochella et al., 2008).

Experiments with the other synthesised powders $\left(\mathrm{MgFeSiO}_{4}\right.$ and $\left.\mathrm{FeSiO}_{3} / \mathrm{MgFeSiO}_{3}\right)$ showed that $k$ was lower by a factor of 2-5 compared with $\mathrm{Fe}_{2} \mathrm{SiO}_{4}$ under comparable conditions i.e. longer times were required for the complete conversion to $\mathrm{Fe}^{3+}$ ions, which was nevertheless observed for all powders under all conditions. For example, at $273 \mathrm{~K}$ for $75 \% \mathrm{Wt}$ acid solutions, $k=2.5 \times 10^{-3} \mathrm{~s}^{-1}$ $\left(\mathrm{MgFeSiO}_{4}\right), 3.0 \times 10^{-3} \mathrm{~s}^{-1}\left(\mathrm{FeSiO}_{3}\right)$ and $1.2 \times 10^{-3} \mathrm{~s}^{-1}$ $\left(\mathrm{MgFeSiO}_{3}\right)$, compared with $5.6 \times 10^{-3} \mathrm{~s}^{-1}$ for $\mathrm{Fe}_{2} \mathrm{SiO}_{4}$. These trends are consistent with the reported slower dissolution behaviour, particularly at lower temperatures, of the more Fe-depleted olivines and of the pyroxene mineral series (Siever and Woodford, 1979; Burns, 1993; Stopar et al., 2006).

\section{Modelling MSPs in the middle atmosphere}

A 3-D Chemistry Climate Model (CCM) - UMSLIMCAT was used to study the atmospheric transport of MSPs and the heterogeneous uptake of $\mathrm{H}_{2} \mathrm{SO}_{4}$. UMSLIMCAT is based on the UK Met Office Unified Model (UM) with a stratospheric chemistry scheme from the SLIMCAT model (Chipperfield, 2006). The CCM is described in detail elsewhere (Tian and Chipperfield, 2005). Briefly, the model has 64 vertical levels from the surface to $0.01 \mathrm{hPa}(\sim 80 \mathrm{~km})$ and a horizontal resolution of $2.5^{\circ} \times 3.75^{\circ}$. The chemical and source gas boundary conditions are similar to those used in the ChemistryClimate Model Validation Activity for SPARC (CCMVal-2) REF0 simulation (Morgenstern et al., 2010).

Previous 1-D and multi-dimensional modelling studies of MSP transport from the mesosphere to the stratosphere have treated microphysical processes such as Brownian coagulation and gravitational sedimentation (Megner et al., 2006; Bardeen et al., 2008; Megner et al., 2008). Sensitivity tests in the study of Bardeen et al. (2008), who used the Whole Atmosphere Community Climate Model (WACCM), concluded that sedimentation/coagulation only has a significant effect on the volumetric MSP mass above $70 \mathrm{~km}$, close to the top level $(80 \mathrm{~km})$ in UMSLIMCAT. Initial test runs with UMSLIMCAT where Brownian coagulation was included indicated no significant effect on the transport of MSP particle mass by sedimentation/coagulation. This is because sedimentation of these small particles, even after coagulation, is very slow.

It is worth noting that, to the best of our knowledge, there is actually no direct evidence that coagulation of MSPs occurs in the atmosphere. There is good evidence from rocketborne charged particle detectors and incoherent scatter radar analysis that small primary MSPs (radius $1-2 \mathrm{~nm}$ ) form above $80 \mathrm{~km}$ (Rapp et al., 2007), but conjectures about when and how subsequent coagulation occurs are based on laboratory studies (e.g. Saunders and Plane, 2011). Almost all previous MSP models have assumed that coagulation occurs solely through Brownian motion-collisions which maintain particles of spherical shape and compact structure. In fact, in our laboratory studies where analogue MSPs consisting of Fe-Mg silicates were synthesised, fractal-like morphologies were consistently observed and explained by the role of magnetic dipole-induced aggregation of Fe-containing particles. As we have shown previously (Saunders et al., 2007), magnetic dipole-induced aggregation can reduce the particle number in the upper stratosphere by over an order of magnitude. However, there is another point to consider: in the atmosphere these particles form and grow in a huge excess of $\mathrm{H}_{2} \mathrm{O}\left(\sim \times 10^{5}\right.$ greater concentration), so that hydroxylation of the particles may reduce the magnetic-dipole driven coagulation rate, as well as the degree of porosity of the particles.

In light of these observations, and since the primary quantity that is required for assessing stratospheric impacts on 
$\mathrm{H}_{2} \mathrm{SO}_{4}$ and SSA is the volumetric mass, we adopted a simplified modelling approach with UMSLIMCAT, whereby MSPs were treated as an advective tracer of nominal (spherical) size subject to eddy diffusion and the calculated wind fields. The tracer mixing ratio in the top level of UMSLIMCAT was held constant, set to a value (see below) calculated from the total particle number derived from the output of a 1D particle growth/transport model (Saunders et al., 2007). The 1-D model is initiated using a chosen global meteoric mass influx (tonnes per day) with particle transport driven by vertical eddy diffusion, and particle growth treated using parameterisations for both Brownian and magnetic-dipole driven coagulation (Saunders and Plane, 2006; Saunders et al., 2007). Gravitational sedimentation is also included, using a Stokes Law parameterisation, at all levels $(110 \mathrm{~km}$ downwards) in the 1-D model. A mean tracer radius of $\sim 1.5 \mathrm{~nm}$ (mass $=2.8 \times 10^{-20} \mathrm{~g}$, assumed particle density $=2.0 \mathrm{~g} \mathrm{~cm}^{-3}$ ) was calculated from the 1-D output of total particle number and surface area. This is only slightly larger than the value of $1.3 \mathrm{~nm}$ chosen in the original 1-D modelling study of MSPs in the mesosphere and stratosphere (Hunten et al., 1980).

In UMSLIMCAT, particles were assumed to be removed at the Earth's surface by dry deposition. This was simulated by removing a nominal $10 \%$ of particles in the lowest model level at each time step (1800 s); these particles were then stored as a non-advected tracer. The sensitivity of the model to the choice of fractional removal in the lowest level was tested by repeating runs with $1 \%$ and $100 \%$ removal per time step. Changing the removal rate resulted in small $(<5 \%)$ differences to the predicted particle numbers in the stratosphere and above (the region of interest in this study), whilst causing more significant differences $(>50 \%)$ at altitudes below $12 \mathrm{~km}$. All simulations were initialised with parameters for the year 2000, and were run for a total of five years following an initial five year spin-up period.

To investigate the impact of MSPs on $\mathrm{H}_{2} \mathrm{SO}_{4}$ removal above $35 \mathrm{~km}$, the model $\mathrm{H}_{2} \mathrm{SO}_{4}$ concentration at $35 \mathrm{~km}$ was set at $5 \times 10^{6} \mathrm{~cm}^{-3}$, consistent with the mid-range of measurements at this altitude (Arnold et al., 1981; Viggiano and Arnold, 1981; Schlager and Arnold, 1987). The uptake of $\mathrm{H}_{2} \mathrm{SO}_{4}$ molecules on smoke particles was treated using firstorder kinetics, such that the loss rate $\left(\mathrm{cm}^{-3} \mathrm{~s}^{-1}\right)$ is given by

$\frac{d\left[\mathrm{H}_{2} \mathrm{SO}_{4}\right]}{d t}=-\frac{\bar{c}}{4} \gamma A\left[\mathrm{H}_{2} \mathrm{SO}_{4}\right]$

where $\bar{c} \approx 1469 \times \sqrt{T}$ is the mean thermal velocity $\left(\mathrm{cm} \mathrm{s}^{-1}\right)$ of an $\mathrm{H}_{2} \mathrm{SO}_{4}$ molecule at temperature $T, \gamma$ is the heterogeneous uptake coefficient, and $A$ is the volumetric particle surface area $\left(\mathrm{cm}^{2} \mathrm{~cm}^{-3}\right)$. Four simulations were performed using $\gamma$ values ranging from zero to 0.01 .

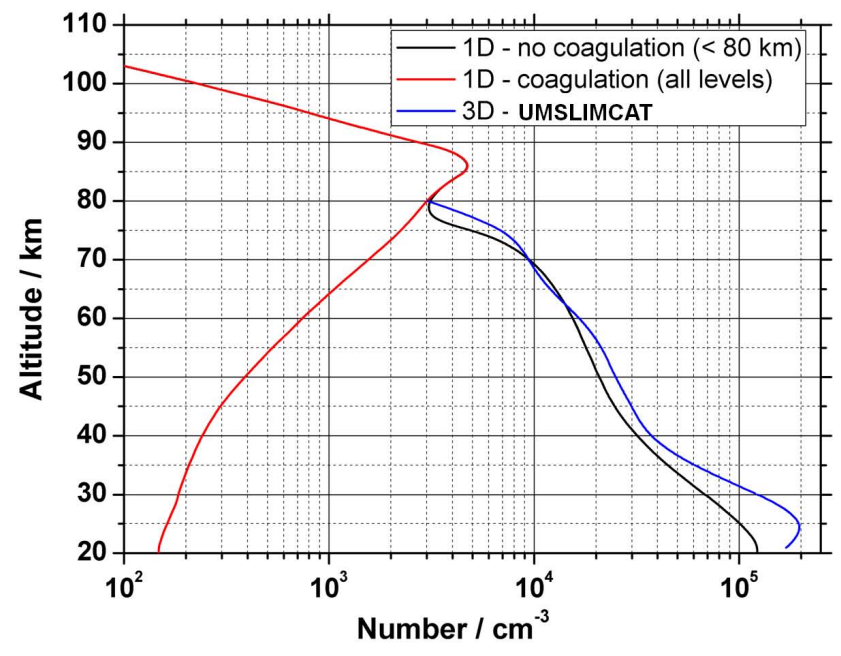

Fig. 4. Vertical profiles of the MSP concentration predicted by the 1D model for the case where there is coagulation below $80 \mathrm{~km}$ (red line) or coagulation is switched off (black line). The global meteoric mass input rate is $22 \mathrm{td}^{-1}$. The blue line shows the MSP density profile calculated by UMSLIMCAT for June at $65^{\circ} \mathrm{S}$.

\subsection{1-D modelling of MSP growth and transport}

A number of runs were performed with the 1-D model using a varying meteoric mass input in order to optimise the 3-D tracer input number concentration (mixing ratio) at $80 \mathrm{~km}$ for the purpose of matching (i) the reported meteoric metal content $(0.5-1.0 \mathrm{Wt} \% \mathrm{Fe})$ in sampled SSA (Murphy et al., 1998; Cziczo et al., 2001) and (ii) measured particle extinction in the mesosphere and upper stratosphere (Hervig et al., 2009). The 1-D model was run in each case for a period of $5 \mathrm{yr}$ to ensure a steady-state particle mass distribution throughout the full altitude range $(110 \mathrm{~km}-20 \mathrm{~km})$.

Figure 4 shows the altitude profile of the total (size integrated) MSP number concentration predicted with a meteoric input of $22 \mathrm{td}^{-1}$, which results in 3000 particles $\mathrm{cm}^{-3}$ at $80 \mathrm{~km}$. Similar profiles are obtained for other input rates with, for example, particle numbers of 4000 and $2200 \mathrm{~cm}^{-3}$ at $80 \mathrm{~km}$ for 44 and $11 \mathrm{td}^{-1}$, respectively. These MSP concentrations are typical of values reported from rocket-borne dust detector measurements in the upper mesosphere (Gelinas et al., 2005; Lynch et al., 2005; Rapp et al., 2007).

Results are shown for scenarios in which particle growth (starting from a "molecular" size particle of $0.3 \mathrm{~nm}$ radius) is treated assuming coagulation at all altitudes (red line), and then where the coagulation is turned off below $80 \mathrm{~km}$ (black line). Although the effect of coagulation is seen to significantly reduce particle numbers below $80 \mathrm{~km}$ in the 1$\mathrm{D}$ model, this is due to the high number of small particles (radius $<1.5 \mathrm{~nm}$ ) which dominate the size distribution in the mesosphere. Conversion of the 1-D model generated particle numbers shown in Fig. 4 to volumetric mass data confirms that coagulation/sedimentation plays no significant role 
below $40 \mathrm{~km}$ : the difference in volumetric mass is $<25 \%$ between the model runs with coagulation/sedimentation turned on and off. Advection in the 3-D model dominates the transport of such small particles, therefore making coagulation a comparatively unimportant process as verified in the initial test runs with UMSLIMCAT and by Bardeen et al. (2008).

\subsection{3-D modelling of MSP transport to the lower stratosphere}

UMSLIMCAT was run with the MSP tracer concentration at $80 \mathrm{~km}$ fixed to $3000 \mathrm{~cm}^{-3}$. Following spin up, the model was run for $5 \mathrm{yr}$ and the particle number density for the same month in each year averaged to remove year-to-year fluctuations. The resulting particle number density was then converted to the volumetric mass of MSP Fe (assuming an olivine composition of $\mathrm{MgFeSiO}_{4}$ ), since this measure of MSP distribution does not depend on the degree of particle coagulation (see above). Figure 5 shows the monthly mean $\mathrm{Fe}$ volumetric mass as a function of height and latitude for January, April, July and October. The downward transport of MSPs in the winter polar vortices from the mesosphere into the stratosphere is evident, as has been noted in previous modelling studies (Bardeen et al., 2008; Megner et al., 2008). MSPs are then redistributed to lower latitudes in the stratosphere by the Brewer-Dobson circulation. We note that the UMSLIMCAT volumetric MSP mass values (for the optimised flux of $22 \mathrm{td}^{-1}$ ) are in good agreement (within a factor of 2 and generally better than $\pm 25 \%$ ) with the CHEM2D study (Megner et al., 2008), whereas the WACCM study (Bardeen et al., 2008) is generally $80 \%$ higher. The CHEM2D and WACCM model studies used the same meteoric flux of $44 \mathrm{t} \mathrm{d}^{-1}$, but the WACCM masses are generally a factor of 2-3 times larger than CHEM2D, with some areas in the polar and mid-latitude stratosphere being higher by up to an order of magnitude.

Meteoric Fe was sampled in SSA by Cziczo et al. (2001) during the months of April and May, from aircraft flights which covered latitudes $9-46^{\circ} \mathrm{N}$ at altitudes up to $19 \mathrm{~km}$ (see the black box outlined in the panel for April in Fig. 5). For the meteoric mass input rate of $22 \mathrm{td}^{-1}$, a mean volumetric mass of meteoric Fe of $(1.2 \pm 0.4) \times 10^{-15} \mathrm{~g} \mathrm{~cm}^{-3}$ would be available for incorporation into SSA. Monthly zonal mean SSA surface area density data from the SAGE II satellite (Thomason et al., 1997) indicate a mean aerosol surface area of $(8 \pm$ 1) $\times 10^{-9} \mathrm{~cm}^{2} \mathrm{~cm}^{-3}$ for the relevant latitudes and altitudes, which would provide a SSA mass of $1.1 \times 10^{-13} \mathrm{~g} \mathrm{~cm}^{-3}$ assuming a mean radius of $250 \mathrm{~nm}$ and density of $1.63 \mathrm{~g} \mathrm{~cm}^{-3}$ (i.e. a $75 \mathrm{Wt} \%$ acid droplet) and a concentration of $1 \mathrm{~cm}^{-3}$ (Junge and Manson, 1961; Deshler, 2008). Therefore, if all of the meteoric $\mathrm{Fe}$ in MSPs is incorporated into available $\mathrm{SSA}$, this would give a figure of $1.1 \mathrm{Wt} \% \mathrm{Fe}$ which is in good accord with the 0.5-1.0 \% range reported by Cziczo et al. (2001).

\subsection{MSP light extinction calculations}

The SOFIE spectrometer on the NASA AIM (Aeronomy of Ice in the Mesosphere) satellite has a sufficiently high signalto-noise to observe optical extinction by MSPs (Hervig et al., 2009). Particle extinction measurements (in units of $\mathrm{km}^{-1}$ ) at a wavelength of $1.037 \mu \mathrm{m}$ were made over the height range $40-75 \mathrm{~km}$ during June at $65^{\circ} \mathrm{S}$. These measurements therefore provide a further way to test the UMSLIMCAT results, though for reasons set out below we regard this as a less stringent test. The modelled extinction was calculated using the MSP number concentration profile from UMSLIMCAT shown in Fig. 4 (note the satisfactory agreement between the 3-D and the 1-D (no coagulation) model profiles in this figure). Rayleigh theory for the $1.5 \mathrm{~nm}$ radius particles was assumed, as well as an olivine $\left(\mathrm{MgFeSiO}_{4}\right)$ composition with real and imaginary refractive indices of 1.73 and 0.07 at $1.037 \mu \mathrm{m}$, respectively (Dorschner et al., 1995). At this particle size and for this composition, absorption is the dominant process with an associated cross section per particle of $7.5 \times 10^{-17} \mathrm{~cm}^{2}$, compared with the scattering cross-section of $2.0 \times 10^{-22} \mathrm{~cm}^{2}$. The olivine composition is chosen based on our recent laboratory study of MSP analogue formation (Saunders and Plane, 2011).

Figure 6 shows reasonable agreement, with the SOFIE data being $\sim 3$ times greater than modelled at $40 \mathrm{~km}$, and the modelled extinction being $\sim 4$ times greater at $75 \mathrm{~km}$. Although these differences are relatively small in magnitude, the discrepancy above $50 \mathrm{~km}$ may reflect several factors (apart from systematic errors in the satellite measurements and model predicted particle distribution): (i) uncertainty in the chosen MSP composition; (ii) deviations in the refractive indices of amorphous nanoparticles, compared with the bulk crystalline mineral values used in the calculation; and (iii) deviation from spherical particle shape. Concerning points (i) and (ii), subsequent analysis of the SOFIE data at additional wavelengths indicates that the assumed olivine composition provides a best fit candidate compared with other possible MSP compositions (presentation by Mark Hervig, $38^{\text {th }}$ COSPAR Scientific Assembly, Bremen, 2010). However, the fitting procedure necessarily assumes that the bulk refractive index is applicable to small nanoparticles (for which no such data currently exists) when determining the optical properties of MSPs. The size dependence at the nano-scale of the imaginary (absorption) index $\kappa$ for a given particle composition has long been discussed with regard to interstellar dust grains (e.g. Huffman, 1977). Such effects could provide an explanation for the differences observed in Fig. 6 above $50 \mathrm{~km}$. For example, reducing $\kappa$, whose bulk value is 0.07 at $1.037 \mu \mathrm{m}$, by a factor of 4 brings the calculated extinction into agreement with the SOFIE data point at $75 \mathrm{~km}$.

Concerning point (iii), at lower altitudes the extinction measured by SOFIE most likely results from MSPs which have agglomerated to form non-spherical (fractal) morphologies (the red line in Fig. 4). To evaluate whether this could 

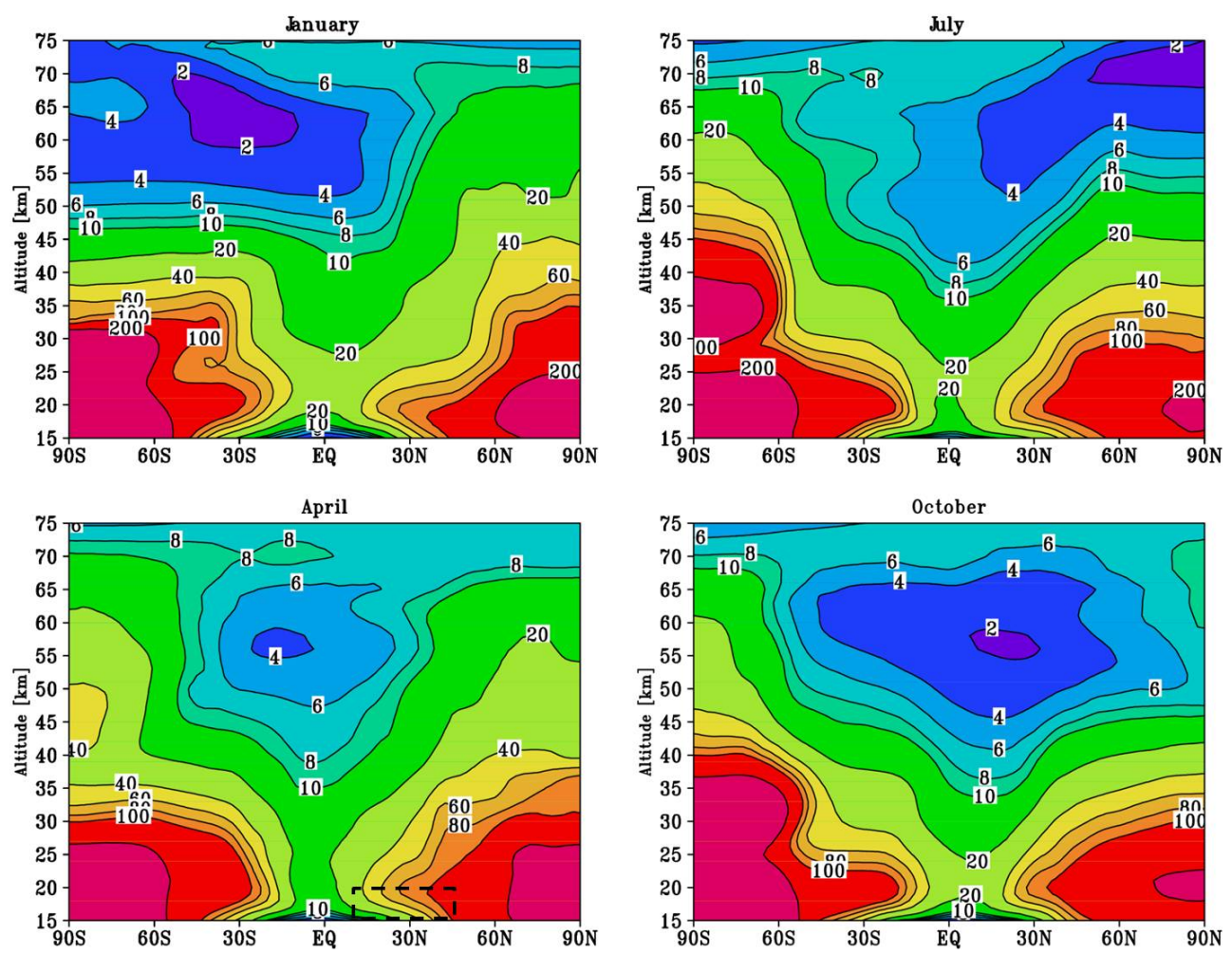

Fig. 5. Volumetric mass of MSP Fe $\left(\times 10^{-17} \mathrm{~g} \mathrm{~cm}^{-3}\right)$ calculated from the monthly mean MSP number densities from 2000-2005, predicted by UMSLIMCAT (global meteoric mass input rate $=22 \mathrm{td}^{-1}$ ). The dashed outlined box in the plot for April indicates altitude and latitude ranges relevant to the measurements of Fe content in SSA (see text).

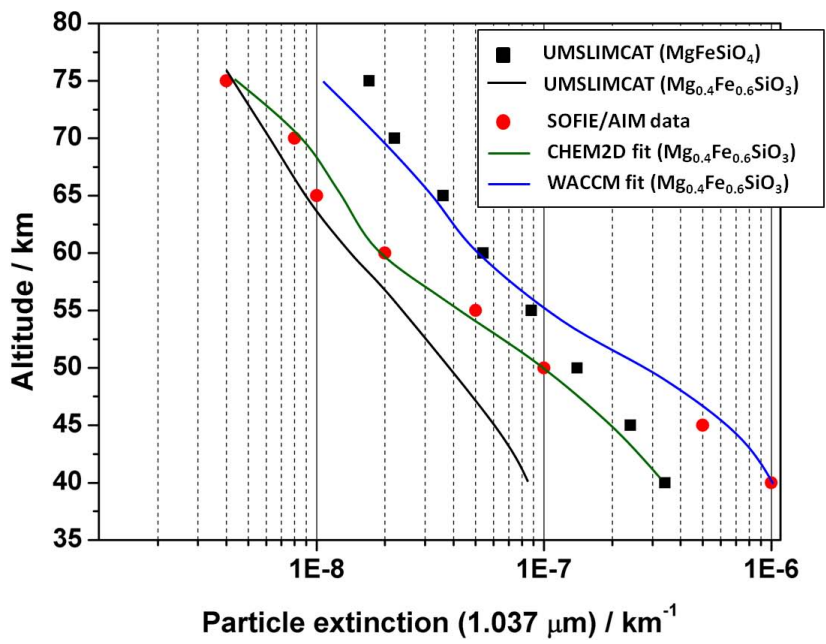

Fig. 6. Comparison of measured MSP extinction (labelled SOFIE/AIM) with values calculated using MSP number concentrations from the UMSLIMCAT model and Rayleigh theory for an assumed olivine $\left(\mathrm{MgFeSiO}_{4}\right)$ composition, and for the same pyroxene species $\left(\mathrm{Mg}_{0.4} \mathrm{Fe}_{0.6} \mathrm{SiO}_{3}\right)$ used to fit the SOFIE data in Hervig et al. (2009). Also shown are the predicted MSP extinction profiles from the WACCM and CHEM2D models, reproduced from Figure 2 in Hervig et al. (2009). explain the modelled extinction below $50 \mathrm{~km}$ being lower than observed (Fig. 6), we conducted test calculations for aggregates composed of a varying number $\left(N_{p}\right)$ of primary particles (radius $r_{p}$ ), with the fractal dimension $D_{f}$ ranging from 1.5 to 2.0. Refractive indices were calculated using Maxwell-Garnett theory over a range of particle porosities $(P=0.1-0.9)$ (Saunders et al., 2007). The particle extinction was estimated using Mie theory with an effective (fractal) particle radius $r_{f}\left(=r_{p} \times \mathrm{N}_{p}^{(1 / D f)}\right)$. There is no unique combination of $D_{f}, N_{p}$ and $P$ which provides a fit but, for example, for $D_{f}=1.75, N_{p}=8$ (giving a fractal radius of $4.9 \mathrm{~nm}$ ), and $P=0.5$ (complex refractive index $m=1.37-i 0.04$ ), the SOFIE extinction at $40 \mathrm{~km}$ can be matched by the modelled extinction. Similar porosity values are required when considering differences in the calculated extinction values resulting from our 1-D model data for the scenarios of coagulation and no coagulation (shown in Fig. 4) below $80 \mathrm{~km}$.

Another factor to consider is that the uptake of acids such as $\mathrm{H}_{2} \mathrm{SO}_{4}$ (see below) and water may cause the MSP size to increase. For example, increasing the tracer radius from 1.5 to just $2.2 \mathrm{~nm}$, but maintaining the number density, would also provide a match to the SOFIE extinction at $40 \mathrm{~km}$. Chemical weathering of the particle surfaces, or ultimately dissolution of the particles in an aqueous-acid medium, could also alter the refractive indices of the MSPs. 
Figure 6 also shows the fitted profiles from Hervig et al. (2009) for the pyroxene species indicated in the figure legend, and MSP numbers obtained from the WACCM and CHEM2D models, together with the extinction profile predicted by UMSLIMCAT assuming the bulk refractive index data for the same pyroxene $(m=1.68-i 0.017$ at $1.037 \mu \mathrm{m})$. This shows that CHEM2D and UMSLIMCAT agree well above $60 \mathrm{~km}$ (for the pyroxene composition), CHEM2D fits well down to $50 \mathrm{~km}$, and WACCM below $45 \mathrm{~km}$. Although the MSP volumetric masses predicted by UMSLIMCAT are in good agreement with those of CHEM2D/WACCM (as noted in the previous section), the difference in the slope of our fits to those of the other models results from the differences in the height-resolved number densities which arise because CHEM2D and WACCM included Brownian coagulation.

With all the uncertainties discussed above (e.g. particle shape, size and composition, precise nature of the coagulation mechanism, questionable validity of bulk material refractive index data applied to nanoparticles, and the effect of chemical weathering), we regard the good fits of the absolute extinctions predicted by the models at various altitudes as somewhat fortuitous. We therefore merely use our extinction data for olivine and pyroxene in this figure to show that we obtain reasonable (to within an order of magnitude) agreement with the SOFIE data by optimising the meteoric flux at $22 \mathrm{t} \mathrm{d}^{-1}$, and emphasise that this also produces a good match to the MSP concentrations measured in the mesosphere and the $\mathrm{Fe} \mathrm{Wt} \%$ measured in SSA.

\subsection{3-D modelling results of $\mathrm{MSP}-\mathrm{H}_{2} \mathrm{SO}_{4}$ interactions in the stratosphere}

Using a tracer concentration based on the $22 \mathrm{td}^{-1}$ mass input, UMSLIMCAT was run to investigate $\mathrm{H}_{2} \mathrm{SO}_{4}$ loss on MSPs. Figure 7 shows the corresponding profile of predicted $\mathrm{H}_{2} \mathrm{SO}_{4}$ concentrations at $44^{\circ} \mathrm{N}$ (from where all measured data is reported) from above $30 \mathrm{~km}$ for $\gamma=0,10^{-4}, 10^{-3}$ and 0.01 as indicated in the legend. At $45 \mathrm{~km}$, the $\gamma=0.01$ data falls within the measured data error bar with $\left[\mathrm{H}_{2} \mathrm{SO}_{4}\right]$ set to $5 \times 10^{6} \mathrm{~cm}^{-3}$ at $35 \mathrm{~km}$, which is in the middle of the measured range (shown by the coloured points in Fig. 7). It is clear that $\gamma$ would need to be greater than 0.01 if heterogeneous acid loss to particles is the sole significant depletion process for $\mathrm{H}_{2} \mathrm{SO}_{4}$ in the upper stratosphere. If coagulation of MSPs does occur to a significant extent, then the consequent reduction in available surface area would require an even higher uptake coefficient (i.e. still consistent with our lower limit) in order to match the measured acid data above $40 \mathrm{~km}$. Subsequent chemical reactions or phase changes at particle surfaces and the separate loss process of photolysis have been assessed in previous modelling work (e.g. Mills et al., 2005), which showed that they will occur on much longer timescales than heterogeneous uptake and therefore be less important removal processes.

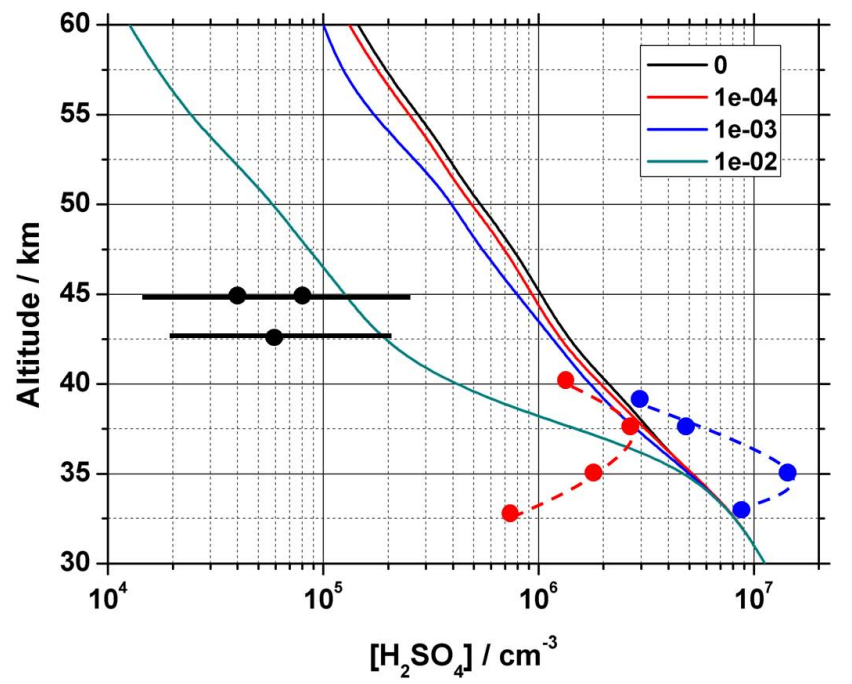

Fig. 7. Altitude profiles at $44^{\circ} \mathrm{N}$ of the $\mathrm{H}_{2} \mathrm{SO}_{4}$ concentration modelled in UMSLIMCAT with the heterogeneous uptake coefficients $(\gamma)$ of $\mathrm{H}_{2} \mathrm{SO}_{4}$ on MSPs indicated in the legend. The solid points are balloon-borne measurements (blue - Viggiano and Arnold, 1981; red - Schlager and Arnold, 1987; black, with error bar - Arijs et al., 1985).

A final point is whether there are actually sufficient metal atoms in MSPs to remove the adsorbed $\mathrm{H}_{2} \mathrm{SO}_{4}$. The number of metal atoms present in MSPs between 30 and $45 \mathrm{~km}$ can be compared with the $\mathrm{H}_{2} \mathrm{SO}_{4}$ concentration profile when $\gamma=0$ (i.e. no smoke present). Assuming a molecular olivine radius of $0.3 \mathrm{~nm}$, the $1.5 \mathrm{~nm}$ radius tracer particle would contain 125 molecules. Therefore at $45 \mathrm{~km}$, from the predicted MSP number, the total number of metal $(\mathrm{Fe}+\mathrm{Mg})$ atoms is $1.1 \times 10^{7} \mathrm{~cm}^{-3}$ - equivalent to a mixing ratio of $\sim 2.2 \times 10^{-10}$. This compares with an acid mixing ratio of $\sim 8 \times 10^{-11}$ at the same altitude i.e. an excess of metal atoms would be available in the upper stratosphere for the heterogeneous removal of $\mathrm{H}_{2} \mathrm{SO}_{4}$. This ratio of 2.8 decreases at lower altitudes to below 2.0 at $\sim 42 \mathrm{~km}$ (consistent with increasing acid levels) and to 0.6 at $30 \mathrm{~km}$.

\section{Discussion and atmospheric implications}

\subsection{Dissolution of MSPs in $\mathrm{H}_{2} \mathrm{SO}_{4} / \mathrm{H}_{2} \mathrm{O}$ mixtures}

The measured rate coefficients $(k)$ describe the overall rate of a complex mechanism of competing processes which convert $\mathrm{Fe}^{2+}$ in solid silicate particles to $\mathrm{Fe}^{3+}$ species in solution. Although the rate-limiting step is not explicitly identified, the observed trends in $k$ suggest that, due to increased solution viscosity at lower temperatures/higher $\mathrm{Wt} \%$ acid, the diffusion of $\mathrm{H}_{2} \mathrm{SO}_{4}$ molecules to the particle surface is an important controlling factor. Oxidation of $\mathrm{Fe}^{2+}$ to $\mathrm{Fe}^{3+}$ under such highly acidic conditions is likely to be rapid, and the observation that the ratio of bare $\mathrm{Fe}^{3+}$ to complexed $\mathrm{Fe}^{3+}$ (measured 
by the ratio of absorbance peaks in the spectra) was constant during the course of the reaction indicates that the dissolution and ion-complexation processes are also fast. There has been much discussion in the literature regarding the mechanisms of silicate mineral weathering e.g. Schott and Berner (1983); Casey and Westrich (1992) and Liu et al. (2006).

The amorphous silicate powders displayed significantly faster dissolution compared with crystalline $\mathrm{Fe}^{2+}$ compounds. For example, experiments with Mohr's salt added to a $75 \% \mathrm{Wt}$ acid solution, indicated that after $24 \mathrm{~h},<10 \%$ of the $\mathrm{Fe}^{2+}$ had been converted to $\mathrm{Fe}^{3+}$. The lower solubility/dissolution of crystalline compounds is consistent with the study of Wise et al. (2003), although their conclusion that $\mathrm{Fe}^{2+}$ is the exclusive species remaining in solution is contradicted by the spectral analysis in the present study. Clearly, a distinct structural effect is evident, with an amorphous particle form promoting faster reaction and dissolution. This was further verified by a comparison of the dissolution rates of high purity amorphous and crystalline ferric oxide $\left(\mathrm{Fe}_{2} \mathrm{O}_{3}\right)$ powders. The former, synthesised in our laboratory via a photo-oxidation method (Saunders and Plane, 2006), was found to result in $100 \%$ dissolution within $12 \mathrm{~h}$ in a $75 \% \mathrm{Wt}$ solution at $295 \mathrm{~K}$, whereas a commercial crystalline sample exhibited only $\sim 20 \%$ dissolution after 24 hours under the same conditions. The disparity in dissolution rates between crystalline and amorphous compounds is also consistent with the reported enhanced solubility of amorphous silica $\left(\mathrm{SiO}_{2}\right)$ at $T \geq 273 \mathrm{~K}$ compared with that of crystalline quartz e.g. (Gunnarsson and Arnorsson, 2000).

Regarding the fate of magnesium and silicon from dissolved MSPs within SSA, the most likely species formed are highly soluble hydrated magnesium sulphate and silicic acid $\left(\mathrm{H}_{4} \mathrm{SiO}_{4}\right)$, respectively. Neither of these end products has any significant UV-Vis absorption features and so are not detectable with the technique employed to monitor the presence of $\mathrm{Fe}$ ions in this study. $\mathrm{Mg}$ ion peaks are evident in the PALMS stratospheric aerosol spectra reported in the studies of Murphy et al. (1998) and Cziczo et al. (2001), whilst unassigned peaks are also present at mass number 28 which would be consistent with $\mathrm{Si}^{+}$ions.

The observed dissolution rates of the amorphous meteoric smoke analogue powders in $\mathrm{H}_{2} \mathrm{SO}_{4}-\mathrm{H}_{2} \mathrm{O}$ solutions at temperatures down to $223 \mathrm{~K}$ indicate that the dissolution of MSPs within SSA in the Junge layer will occur within a few days. Prior to dissolution, the collision between an MSP and an SSA with radii of $1.5 \mathrm{~nm}$ and $250 \mathrm{~nm}$, respectively, resulting purely from Brownian motion under conditions relevant to the lower stratosphere, would take $\sim 4$ days (coagulation kernel $\beta \sim 3.4 \times 10^{-6} \mathrm{~cm}^{3} \mathrm{~s}^{-1}-$ see Eq. (E2) in Saunders and Plane (2006), and assuming a SSA number concentration of $1 \mathrm{~cm}^{-3}$ ).

The greater observed solubility/dissolution of amorphous $\mathrm{Fe}^{2+}$ minerals, compared with those of a crystalline nature, suggests that more of the $\mathrm{Fe}$-content within stratospheric aerosol is likely to be in the form of soluble bare or sulphate- complexed $\mathrm{Fe}^{3+}$ ions (stabilised against conversion to solidphase iron oxide/hydroxide species by the low temperature/low $\mathrm{pH}$ environment within the droplets). One possible ramification of such enhanced particle solubilities within supercooled SSA would be a reduced potential for MSPs to remain as solid particles and nucleate PSCs below $200 \mathrm{~K}$, at the low saturation ratios proposed by Voigt et al. (2005). Conversely, an enhanced free (cation) or complexed metal anion composition within SSA could provide an increased role for the ion-induced nucleation of such species.

\subsection{Removal of $\mathrm{H}_{2} \mathrm{SO}_{4}$ in the upper stratosphere/lower mesosphere}

The rate of input of interplanetary dust particles to the Earth's atmosphere has been the subject of much recent debate, with estimates ranging from $\sim 5-300 \mathrm{t} \mathrm{d}^{-1}$ (Vondrak et al., 2008). Our optimised level of $22 \mathrm{td}^{-1}$, used to account for the measured metal content in SSA and for fitting the observed particle extinction from the upper stratosphere to the mesosphere, fixes this crucial parameter at the lower end of the currently accepted range.

To our knowledge, there are currently no reported laboratory measurements of the uptake of $\mathrm{H}_{2} \mathrm{SO}_{4}$ onto aerosol of a meteoritic nature. Hence, our conclusion from the modelling exercise that $\gamma \geq 0.01$ should now be tested in the laboratory using appropriate MSP mimics under stratospheric conditions. Reports of the measured uptake of acids such as $\mathrm{HNO}_{3}$ onto mineral (crystalline) dust samples indicate a wide range of uptake coefficient values $\left(10^{-8}<\gamma<0.5\right)$, reflecting the differences in particle size/composition/morphology and in the techniques and conditions employed (see IUPAC Subcommittee on Gas Kinetic Data Evaluation at http://www. iupac-kinetic.ch.cam.ac.uk/ for a summary). This indicates the critical importance of closely replicating materials and conditions for future laboratory measurements of $\mathrm{H}_{2} \mathrm{SO}_{4}$ uptake on MSP analogues under stratospheric conditions.

\section{Conclusions}

Spectroscopic measurements of the acid dissolution of synthesised amorphous iron-rich olivine powders in $\mathrm{H}_{2} \mathrm{SO}_{4}$ solutions of $30-75 \mathrm{Wt} \%$, and at temperatures of $223 \mathrm{~K}-295 \mathrm{~K}$, indicate complete conversion to soluble $\mathrm{Fe}^{3+}$ ions (bare and complexed) under all conditions. The dissolution rate decreases with increasing acid $\mathrm{Wt} \%$ and lower temperature. For the most extreme conditions amenable to our laboratory analysis $(75 \mathrm{Wt} \%$ acid $/ 223 \mathrm{~K})$, corresponding to the midlatitude stratosphere, it is predicted that meteoric smoke particles will fully dissolve in the stratospheric aerosol layer within a week.

Modelling the transport of MSPs from the upper mesosphere to the troposphere indicates that a meteoric mass input rate of about $20 \mathrm{td}^{-1}$ would result in a Fe content in 
stratospheric aerosol that matches the samples collected in the lower stratosphere. The same input also gives a sensible fit to measured particle extinction values from the upper stratosphere to the mesosphere. Of course, this mass input rate depends on the assumptions made about the MSP size and number density in the upper mesosphere, as well as transport in the model, and so is quite uncertain (by at least a factor of 2). At this flux, the model indicates that a heterogeneous uptake coefficient $(\gamma)$ of 0.01 or larger for loss of $\mathrm{H}_{2} \mathrm{SO}_{4}$ vapour on MSPs would be required to account for the observed two orders of magnitude depletion of the acid in the upper stratosphere.

Acknowledgements. This work was funded by the UK Natural Environment Research Council (NERC grant NE/E005659/1). W. S. Tian is supported by the National Basic Research Program of China (2010CB428604).

Edited by: D. J. Cziczo

\section{References}

Arijs, E., Nevejans, D., Ingels, J., and Frederick, P.: Negative-ion composition and sulfuric-acid vapor in the upper-stratosphere, Planet. Space Sci., 31, 1459-1464, 1983.

Arijs, E., Nevejans, D., Ingels, J., and Frederick, P.: Recent stratospheric negative-ion composition measurements between $22-\mathrm{km}$ and 45-km altitude, J. Geophys. Res., 90, 5891-5896, 1985.

Arnold, F., Fabian, R., and Joos, W.: Measurements of the height variation of sulfuric-acid vapor concentrations in the stratosphere, Geophys. Res. Lett., 8, 293-296, 1981.

Bardeen, C. G., Toon, O. B., Jensen, E. J., Marsh, D. R., and Harvey, V. L.: Numerical simulations of the three-dimensional distribution of meteoric dust in the mesosphere and upper stratosphere, J. Geophys. Res., 113, D17202, doi:10.1029/2007JD009515, 2008.

Biermann, U. M., Presper, T., Koop, T., Mossinger, J., Crutzen, P. J., and Peter, T.: The unsuitability of meteoritic and other nuclei for polar stratospheric cloud freezing, Geophys. Res. Lett., 23, 1693-1696, 1996.

Burns, R. G.: Ferric sulfates on Mars, J. Geophys. Res., 92, 570574, 1987.

Burns, R. G.: Rates and mechanisms of chemical-weathering of ferromagnesian silicate minerals on Mars, Geochim. Cosmochim. Acta, 57, 4555-4574, 1993.

Carslaw, K. S., Peter, T., and Clegg, S. L.: Modeling the composition of liquid stratospheric aerosols, Rev. Geophys., 35, 125-154, 1997.

Casey, W. H. and Westrich, H. R.: Control of dissolution rates of orthosilicate minerals by divalent metal oxygen bonds, Nature, 355, 157-159, 1992.

Chipperfield, M. P.: New version of the TOMCAT/SLIMCAT offline chemical transport model: Intercomparison of stratospheric tracer experiments, Quart. J. Roy. Met. Soc., 132, 1179-1203, 2006.

Curtius, J., Weigel, R., Vossing, H. J., Wernli, H., Werner, A., Volk, C. M., Konopka, P., Krebsbach, M., Schiller, C., Roiger, A., Schlager, H., Dreiling, V., and Borrmann, S.: Observations of meteoric material and implications for aerosol nucleation in the winter arctic lower stratosphere derived from in situ particle measurements, Atmos. Chem. Phys., 5, 3053-3069, doi:10.5194/acp5-3053-2005, 2005.

Cziczo, D. J., Thomson, D. S., and Murphy, D. M.: Ablation, flux, and atmospheric implications of meteors inferred from stratospheric aerosol, Science, 291, 1772-1775, 2001.

Deshler, T.: A review of global stratospheric aerosol: Measurements, importance, life cycle, and local stratospheric aerosol, Atmos. Res., 90, 223-232, 2008.

Dorschner, J., Begemann, B., Henning, T., Jager, C., and Mutschke, H.: Steps toward interstellar silicate mineralogy. 2. Study of MgFe-silicate glasses of variable composition, Astron. Astrophys., 300, 503-520, 1995.

Draine, B. T.: Interstellar dust grains, Ann. Rev. Astron. Astroph., 41, 241-289, 2003.

Gelinas, L. J., Lynch, K. A., Kelley, M. C., Collins, R. L., Widholm, M., MacDonald, E., Ulwick, J., and Mace, P.: Mesospheric charged dust layer: Implications for neutral chemistry, J. Geophys. Res., 110, A01310, doi:10.1029/2004JA010503, 2005.

Gumbel, J. and Megner, L.: Charged meteoric smoke as ice nuclei in the mesosphere: Part 1-a review of basic concepts, J. Atmos. Solar-Terr. Phys., 71, 1225-1235, 2009.

Gunnarsson, I., and Arnorsson, S.: Amorphous silica solubility and the thermodynamic properties of $\mathrm{H}_{4} \mathrm{SiO}_{4}$ degrees in the range of $0^{\circ}$ to $350^{\circ} \mathrm{C}$ at $p_{\text {sat }}$, Geochim. Cosmochim. Acta, 64, 22952307, 2000.

Hervig, M. E., Gordley, L. L., Deaver, L. E., Siskind, D. E., Stevens, M. H., Russell, J. M., Bailey, S. M., Megner, L., and Bardeen, C. G.: First satellite observations of meteoric smoke in the middle atmosphere, Geophys. Res. Lett., 36, L18805, doi:10.1029/2009GL039737, 2009.

Hochella, M. F., Lower, S. K., Maurice, P. A., Penn, R. L., Sahai, N., Sparks, D. L., and Twining, B. S.: Nanominerals, mineral nanoparticles, and Earth systems, Science, 319, 1631-1635, 2008.

Huffman, D. R.: Interstellar grains - interaction of light with a smallparticle system, Adv. Phys., 26, 129-230, 1977.

Hunten, D. M., Turco, R. P., and Toon, O. B.: Smoke and dust particles of meteoric origin in the mesosphere and stratosphere, J. Atmos. Sci., 37, 1342-1357, 1980.

Hurowitz, J. A., McLennan, S. M., Tosca, N. J., Arvidson, R. E., Michalski, J. R., Ming, D. W., Schroder, C., and Squyres, S. W.: In situ and experimental evidence for acidic weathering of rocks and soils on Mars, J. Geophys. Res., 111, E02S19, doi:10.1029/2005JE002515, 2006.

Junge, C.E., and Manson, J.E.: Stratospheric aerosol studies, J. Geophys. Res., 66, 2163-2182, 1961.

Liu, Y., Olsen, A. A., and Rimstidt, J. D.: Mechanism for the dissolution of olivine series minerals in acidic solutions, Amer. Mineral., 91, 455-458, 2006.

Loughnan, F. C.: Chemical weathering of the silicate minerals, Elsevier, New York, USA, 154 pp., 1969.

Lynch, K. A., Gelinas, L. J., Kelley, M. C., Collins, R. L., Widholm, M., Rau, D., MacDonald, E., Liu, Y., Ulwick, J., and Mace, P.: Multiple sounding rocket observations of charged dust in the polar winter mesosphere, J. Geophys. Res., 110, A03302, doi:10.1029/2004JA010502, 2005. 
Megner, L., Rapp, M., and Gumbel, J.: Distribution of meteoric smoke - sensitivity to microphysical properties and atmospheric conditions, Atmos. Chem. Phys., 6, 4415-4426, doi:10.5194/acp-6-4415-2006, 2006.

Megner, L., Siskind, D. E., Rapp, M., and Gumbel, J.: Global and temporal distribution of meteoric smoke: A twodimensional simulation study, J. Geophys. Res., 113, D03202, doi:10.1029/2007JD009054, 2008.

Mills, M. J., Toon, O. B., Vaida, V., Hintze, P. E., Kjaergaard, H. G., Schofield, D. P., and Robinson, T. W.: Photolysis of sulfuric acid vapor by visible light as a source of the polar stratospheric CN layer, J. Geophys. Res., 110, D08201, doi:10.1029/2004JD005519, 2005.

Morgenstern, O., Giorgetta, M. A., Shibata, K., Eyring, V., Waugh, D. W., Shepherd, T. G., Akiyoshi, H., Austin, J., Baumgaertner, A. J. G., Bekki, S., Braesicke, P., Bruhl, C., Chipperfield, M. P., Cugnet, D., Dameris, M., Dhomse, S., Frith, S. M., Garny, H., Gettelman, A., Hardiman, S. C., Hegglin, M. I., Jockel, P., Kinnison, D. E., Lamarque, J. F., Mancini, E., Manzini, E., Marchand, M., Michou, M., Nakamura, T., Nielsen, J. E., Olivie, D., Pitari, G., Plummer, D. A., Rozanov, E., Scinocca, J. F., Smale, D., Teyssedre, H., Toohey, M., Tian, W., and Yamashita, Y.: Review of the formulation of present-generation stratospheric chemistryclimate models and associated external forcings, J. Geophys. Res., 115, D00M02, doi:10.1029/2009JD013728, 2010.

Murphy, D. M., Thomson, D. S., and Mahoney, T. M. J.: In situ measurements of organics, meteoritic material, mercury, and other elements in aerosols at 5 to 19 kilometers, Science, 282, 16641669, 1998.

Neely III, R. R., English, J. M., Toon, O. B., Solomon, S., Mills, M., and Thayer, J. P.: Implications of extinction due to meteoritic smoke in the upper stratosphere, Geophys. Res. Lett., 38, L24808, doi:10.1029/2011GL049865, 2011.

Plane, J. M. C.: Atmospheric chemistry of meteoric metals, Chem. Rev., 103, 4963-4984, 2003.

Potterill, R. H., Walker, O. J., and Weiss, J.: Electron affinity spectrum of ferrous ion in aqueous solution, Proc. Roy. Soc. Ldn. A, 156, 561-570, 1936.

Prather, M. J. and Rodriguez, J. M.: Antarctic ozone - meteoric control of $\mathrm{HNO}_{3}$, Geophys. Res. Lett., 15, 1-4, 1988.

Rapp, M. and Thomas, G. E.: Modeling the microphysics of mesospheric ice particles: Assessment of current capabilities and basic sensitivities, J. Atmos. Solar-Terr. Phys., 68, 715-744, 2006.

Rapp, M., Strelnikova, I., and Gumbel, J.: Meteoric smoke particles: Evidence from rocket and radar techniques, Adv. Space Res., 40, 809-817, 2007.

Saunders, R. W. and Plane, J. M. C.: A laboratory study of meteor smoke analogues: Composition, optical properties and growth kinetics, J. Atmos. Solar-Terr. Phys., 68, 2182-2202, 2006.

Saunders, R. W., Forster, P. M., and Plane, J. M. C.: Potential climatic effects of meteoric smoke in the Earth's paleo-atmosphere, Geophys. Res. Lett., 34, L16801, doi:10.1029/2007GL029648, 2007.

Saunders, R. W. and Plane, J. M. C.: A photo-chemical method for the production of olivine nanoparticles as cosmic dust analogues, Icarus, 212, 373-382, 2011.

Scharf, K. and Lee, R. M.: Investigation of spectrophotometric method of measuring ferric ion yield in ferrous sulfate dosimeter, Radiation Res., 16, 115-124, 1962.
Schlager, H. and Arnold, F.: Balloon-borne composition measurements of stratospheric negative-ions and inferred sulfuric-acid vapor abundances during the MAP-GLOBUS 1983 campaign, Planet. Space Sci., 35, 693-701, 1987.

Schott, J. and Berner, R. A.: X-ray photoelectron studies of the mechanism of iron silicate dissolution during weathering, Geochim. Cosmochim. Acta, 47, 2233-2240, 1983.

Siever, R., and Woodford, N.: Dissolution kinetics and the weathering of mafic minerals, Geochim. Cosmochim. Acta, 43, 717-724, 1979.

Stopar, J. D., Taylor, G. J., Hamilton, V. E., and Browning, L.: Kinetic model of olivine dissolution and extent of aqueous alteration on Mars, Geochim. Cosmochim. Acta, 70, 6136-6152, 2006.

Thomason, L. W., Poole, L. R., and Deshler, T.: A global climatology of stratospheric aerosol surface area density deduced from stratospheric aerosol and gas experiment II measurements: 1984 1994, J. Geophys. Res., 102, 8967-8976, 1997.

Thompson, S. P., Evans, A., and Jones, A. P.: Structural evolution in thermally processed silicates, Astron. Astrophys., 308, 309-320, 1996.

Tian, W. S. and Chipperfield, M. P.: A new coupled chemistryclimate model for the stratosphere: The importance of coupling for future $\mathrm{O}_{3}$-climate predictions, Q. J. Roy. Meteor. Soc., 131, 281-303, 2005.

Turco, R. P., Toon, O. B., Hamill, P., and Whitten, R. C.: Effects of meteoric debris on stratospheric aerosols and gases, J. Geophys. Res., 86, 1113-1128, 1981.

Vaida, V., Kjaergaard, H. G., Hintze, P. E., and Donaldson, D. J.: Photolysis of sulfuric acid vapor by visible solar radiation, Science, 299, 1566-1568, 2003.

Viggiano, A. A. and Arnold, F.: Extended sulfuric-acid vapor concentration measurements in the stratosphere, Geophys. Res. Lett., 8, 583-586, 1981.

Voigt, C., Schlager, H., Luo, B. P., Dornbrack, A. D., Roiger, A., Stock, P., Curtius, J., Vossing, H., Borrmann, S., Davies, S., Konopka, P., Schiller, C., Shur, G., and Peter, T.: Nitric acid trihydrate (NAT) formation at low NAT supersaturation in polar stratospheric clouds (PSCs), Atmos. Chem. Phys., 5, 1371-1380, doi:10.5194/acp-5-1371-2005, 2005.

Vondrak, T., Plane, J. M. C., Broadley, S., and Janches, D.: A chemical model of meteoric ablation, Atmos. Chem. Phys., 8, 70157031, doi:10.5194/acp-8-7015-2008, 2008.

White, A. F. and Brantley, S. L.: Chemical weathering rates of silicate minerals, in: Reviews in mineralogy, edited by: Ribbe, P. H., Mineralogical Society of America, Washington, USA, 1995.

Whiteker, R. A. and Davidson, N.: Ion-exchange and spectrophotometric investigation of iron(iii) sulfate complex ions, J. Am. Chem. Soc., 75, 3081-3085, 1953.

Williams, L. R. and Long, F. S.: Viscosity of supercooled sulfuricacid-solutions, J. Phys. Chem., 99, 3748-3751, 1995.

Wise, M. E., Brooks, S. D., Garland, R. M., Cziczo, D. J., Martin, S. T., and Tolbert, M. A.: Solubility and freezing effects of $\mathrm{Fe}^{2+}$ and $\mathrm{Mg}^{2+}$ in $\mathrm{H}_{2} \mathrm{SO}_{4}$ solutions representative of upper tropospheric and lower stratospheric sulfate particles, J. Geophys. Res., 108, 4434, doi:10.1029/2003JD003420, 2003. 